\title{
Microstructural development of interface layers between co-sintered alumina and spinel compacts
}

\author{
Emre Yalamac $^{\mathrm{a}, 1}$, Claude Carry $^{\mathrm{b}, 2}$, Sedat Akkurt ${ }^{\mathrm{a}, *}$ \\ ${ }^{a}$ Mechanical Engineering Department, Izmir Institute of Technology, 35430 Izmir, Turkey \\ b SIMaP, CNRS - Grenoble INP - Université Joseph Fourier, Phelma Campus BP 75, F-38 402 St-Martin d'Hères, France
}

Received 27 October 2010; received in revised form 9 March 2011; accepted 14 March 2011

Available online 9 April 2011

\begin{abstract}
Tests were performed to investigate the microstructure of the interface between alumina and spinel materials after high temperature thermal treatment $\left(1500^{\circ} \mathrm{C}\right)$. The first test involved co-sintering of co-pressed alumina and spinel compacts. Microstructures were investigated by SEM, EDS, WDS and EBSD. A microstructurally distinct layer with columnar grains of up to $40 \mu \mathrm{m}$ length and $5 \mu \mathrm{m}$ width was observed after $16 \mathrm{~h}$ at $1500^{\circ} \mathrm{C}$. Growth rate of the columnar spinel grains from parent spinel towards alumina follows parabolic kinetics, controlled by a mixed process of $\mathrm{O}^{2-}$ ion diffusion and interface reaction. Diffusion couples of spinel and alumina were investigated. Same columnar spinel grains were observed at the interface which grew into alumina during thermal treatment with the same kinetics as in co-sintering experiments. The shape of the phase boundaries between spinel and alumina can be a further indication of the direction of their growth.
\end{abstract}

(C) 2011 Elsevier Ltd. All rights reserved.

Keywords: $\mathrm{Al}_{2} \mathrm{O}_{3}$; Spinels; Interfaces; Sintering; Microstructure-final

\section{Introduction}

When magnesia $(\mathrm{MgO})$ and alumina $\left(\mathrm{Al}_{2} \mathrm{O}_{3}\right)$ are heated together, a spinel $\left(\mathrm{MgO} \cdot \mathrm{Al}_{2} \mathrm{O}_{3}\right)$ phase forms in the middle. This spinel phase stoichiometrically contains $16.9 \% \mathrm{Mg}$ and $38.0 \%$ $\mathrm{Al}$ by weight. The extent of the formation of the spinel phase or the interface between magnesia $(\mathrm{MgO})$ and alumina $\left(\mathrm{Al}_{2} \mathrm{O}_{3}\right)$ has been studied from different perspectives in order to understand if a good bond can be achieved between the two or to investigate the diffusion behaviors of the components. ${ }^{1-3}$ Most of these studies involved heating of diffusion couples, some others involved heating of single/poly crystals of a component in contact with a powder of the second component. In the literature, sintering behavior of co-pressed and co-sintered powders of oxide/oxide, metal/oxide and metal/metal pairs are reported. ${ }^{4-6}$

\footnotetext{
* Corresponding author. Tel.: +90 232750 6705, fax: +90 2327506701.

E-mail addresses: emre.yalamac @ bayar.edu.tr (E. Yalamac), claude.carry@ simap.grenoble-inp.fr (C. Carry), sedatakkurt@iyte.edu.tr (S. Akkurt).

${ }^{1}$ Tel.: +90 232750 6789; fax: +90 2327506701 .

${ }^{2}$ Tel.: +3304768266 19; fax: +330476826744.
}

Co-sintering process is to sinter two materials together when they are in contact with each other, a relatively common technique to fabricate bi-materials. These materials are functionally graded materials, which mean that their gradient properties depend on mechanical, electrical and magnetic properties of their components and also on continuous or stepwise production processing. ${ }^{4}$

Diffusion couple test is a useful and common technique to understand the growth of intermediate new phases between the two end-members (components) which are previously shaped and sintered to some extent. For example, solid state reactions and solid-gas reactions between $\mathrm{Y}_{2} \mathrm{O}_{3}$ and $\mathrm{Fe}_{2} \mathrm{O}_{3}$ systems were studied by Buscaglia et al. who used different types of diffusion couples. ${ }^{7}$ They observed growth of different dense ternary phases at the interfaces. Columnar type elongated grains gained strong adherence between the end-members. Smigelkas and Kirkendall studied the diffusion couples in metals that produce porosity in the interface. ${ }^{8}$ More recently similar porosity in oxide-oxide based diffusion couples was observed. ${ }^{9}$

Reaction paths at the interfaces $\mathrm{AO}-\mathrm{AB}_{2} \mathrm{O}_{4}-\mathrm{B}_{2} \mathrm{O}_{3}$ (e.g. $\mathrm{A}=\mathrm{Mg}, \mathrm{B}=\mathrm{Al}$ ) are discussed by Wagner ${ }^{10}$ and later by Schmalzried. ${ }^{11}$ At the $\mathrm{MgAl}_{2} \mathrm{O}_{4}-\mathrm{Al}_{2} \mathrm{O}_{3}$ interface oxygen and 
cation transport through $\mathrm{MgAl}_{2} \mathrm{O}_{4}$ produces the following reaction

$\mathrm{Mg}^{2+}+\mathrm{O}^{2-}+\mathrm{Al}_{2} \mathrm{O}_{3}=\mathrm{MgAl}_{2} \mathrm{O}_{4}$

Carter investigated the solid-state reaction mechanisms between magnesium oxide and aluminum oxide in his inert marker experiments at high temperature. ${ }^{12} \mathrm{He}$ observed that the solid-state reactions forming $\mathrm{MgAl}_{2} \mathrm{O}_{4}$ occurs by counterdiffusion of the $\mathrm{Mg}^{2+}$ and $\mathrm{Al}^{3+}$ ions through the relatively rigid oxygen lattice of the spinel at the $\mathrm{Al}_{2} \mathrm{O}_{3} / \mathrm{MgO}$-gas interface. He suggested that spinel forms at the $\mathrm{Al}_{2} \mathrm{O}_{3}-\mathrm{MgAl}_{2} \mathrm{O}_{4}$ interface in an amount three times higher than at the $\mathrm{MgO}-\mathrm{MgAl}_{2} \mathrm{O}_{4}$ interface. This was later confirmed by other studies on $\mathrm{MgAl}_{2} \mathrm{O}_{4}$ spinel ${ }^{1,2}$ as well as for $\mathrm{NiAl}_{2} \mathrm{O}_{4}$ spinel. ${ }^{13} \mathrm{~A}$ high resolution electron microscope study of the interface was carried out by Li et al. ${ }^{14}$

The interdiffusion of polycrystalline $\mathrm{MgO}$ and $\mathrm{Al}_{2} \mathrm{O}_{3}$ under atmospheric pressure in the range of $1200-1600{ }^{\circ} \mathrm{C}$ with and without dopant additions was studied by Zhang et al. ${ }^{3}$ Spinel growth showed parabolic law as measured from the ratio of spinel layer thickness versus time. Chemical diffusion coefficient of $\mathrm{Mg}^{2+}$ ions must be somewhat higher than that of the $\mathrm{Al}^{3+}$ ions. Because they found the measured average concentration gradient of $\mathrm{Mg}^{2+}$ to be less than one-and-a-half times that of $\mathrm{Al}^{3+}$ ions. ${ }^{3}$

In another study, spinel phase formation by reaction of either single or polycrystalline periclase with single-crystal corundum was investigated under high pressure and at elevated temperatures. ${ }^{2}$ Spinel composition showed linear variation across the spinel layer from periclase side to corundum side. They observed two different microstructural spinel phase formations, one of them was equiaxed type grains near the periclase side, on the other hand, there were columnar type grains near the corundum side. The ratio of equiaxed to columnar grain region was around 1:3. So they concluded that spinel grows in both directions by consuming periclase and corundum. Thus spinel was formed by counterdiffusion of $\mathrm{Al}^{3+}$ and $\mathrm{Mg}^{2+}$ ions through spinel lattice. At the end of their paper these authors recalled that their model and the data on which it is based do not require mobile oxygen; but they mentioned that "it seems likely that oxygen was mobile in our experiments, although its mobility is not required for spinel growth". Spinel layer formation was significantly effected by applied pressure, temperature and soaking time. ${ }^{2}$ A similar interlayer was observed for $\mathrm{NiAl}_{2} \mathrm{O}_{4}$ growth between diffusion couples of $\mathrm{NiO}$ and $\mathrm{Al}_{2} \mathrm{O}_{3} .{ }^{13}$ Whitney and Stubican ${ }^{15}$ studied the interdiffusion between $\mathrm{MgO}$ and $\mathrm{MgAl}_{2} \mathrm{O}_{4}$ to compare with other studies for $\mathrm{MgO}-\mathrm{Al}_{2} \mathrm{O}_{3}$ interfaces ${ }^{2,3,12}$ but without reporting any interface layer microstructural observation and without considering the necessary mobility of oxygen for spinel layer growth.

Diffusion between $\mathrm{AO}$ and $\mathrm{B}_{2} \mathrm{O}_{3}$ type of oxides in systems of $\mathrm{MgO}-\mathrm{Al}_{2} \mathrm{O}_{3}{ }^{1,14}$ and $\mathrm{NiO}-\mathrm{Al}_{2} \mathrm{O}_{3}{ }^{13}$ was studied using diffusion couples. Some other studies involved vapor phase transport of $\mathrm{Mg}$ to form $\mathrm{MgAl}_{2} \mathrm{O}_{4}{ }^{12,16} \mathrm{Okada}$ et al. investigated spinel formation from different sized powders of $\mathrm{ZnO}$ and $\mathrm{Al}_{2} \mathrm{O}_{3} \cdot{ }^{17}$ The spinel phase in these studies formed in situ. These stud-

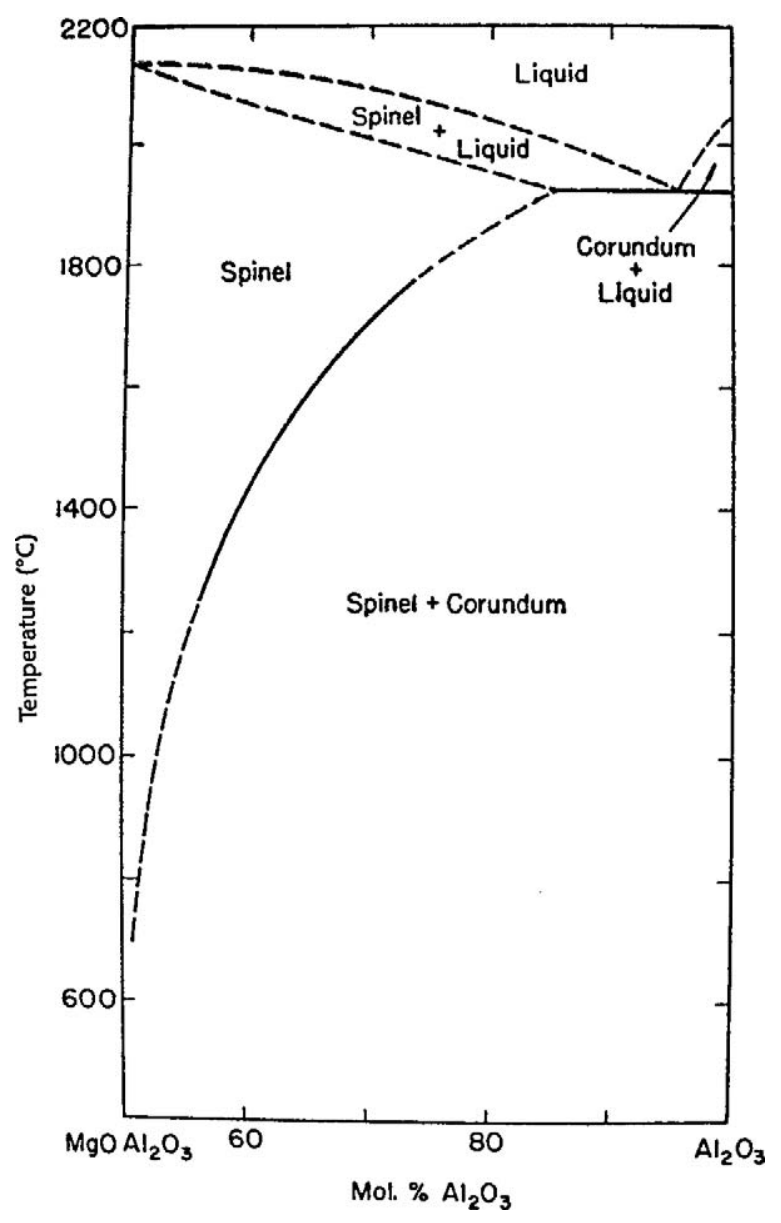

Fig. 1. Spinel-alumina phase equilibrium diagram. ${ }^{18}$

ies were more concerned with physical development of this interlayer from kinetic aspect without much attention on the microstructures. ${ }^{3,12}$

In this study, commercial spinel and alumina powder compacts are used as end-members during co-sintering and diffusion couple tests as opposed to the above studies which produced spinel in situ.

Investigation of diffusion couples of $\mathrm{Al}_{2} \mathrm{O}_{3}$ and $\mathrm{MgO} \cdot \mathrm{Al}_{2} \mathrm{O}_{3}$ should start with the phase equilibrium diagram ${ }^{18}$ of which states that there is negligible solubility for $\mathrm{Mg}^{2+}$ in corundum while there is significant room for solid solubility of $\mathrm{Al}^{3+}$ in spinel (Fig. 1). For example, when alumina is contacted with spinel at $1500^{\circ} \mathrm{C}, \mathrm{Al}^{3+}$ is expected to diffuse into spinel until an aluminarich spinel with $62 \mathrm{~mol} \% \mathrm{Al}_{2} \mathrm{O}_{3}$ is formed. The alumina excess in nonstoichiometric spinel can be accommodated in different ways. ${ }^{19-22}$ It may lead to the introduction of a substitution defect on the tetrahedral magnesium sites and an aluminum vacancy or magnesium vacancy to compensate for the excess positive charge. This reaction can be summarized as

$$
12 \mathrm{Al}_{2} \mathrm{O}_{3} \rightarrow 16 \mathrm{Al}_{\mathrm{Al}}^{x}+36 \mathrm{O}_{\mathrm{O}}^{x}+8 \mathrm{Al}^{\bullet}{ }_{\mathrm{Mg}}+V_{\mathrm{Mg}}^{\prime \prime}+2 V_{\mathrm{Al}}^{\prime \prime \prime}
$$

In the literature formation of vacancies of only $\mathrm{Mg},{ }^{22}$ only $\mathrm{Al}^{19}$ or both ${ }^{20}$ are suggested. There is some limited exchange between the two cation sites so that some tetrahedral sites are occupied by $\mathrm{Al}^{3+}$ ions and some octahedral sites are occu- 
Table 1

Measured physical and chemical properties of the powders.

\begin{tabular}{|c|c|c|c|c|}
\hline & & Alumina A & Alumina B & Spinel \\
\hline \multicolumn{2}{|l|}{$d_{50}(\mu \mathrm{m})$ by Sedigraph } & 0.35 & 0.18 & 0.19 \\
\hline \multicolumn{2}{|c|}{ Specific surface area BET $\left(\mathrm{m}^{2} / \mathrm{g}\right)$} & 14.30 & 13.30 & 31 \\
\hline \multicolumn{2}{|c|}{$d_{\mathrm{BET}}(\mu \mathrm{m})$ calculated from BET data } & 0.105 & 0.113 & 0.055 \\
\hline \multirow[t]{6}{*}{ Chemical analysis $(\mathrm{ppm})^{\mathrm{a}}$} & $\mathrm{Na}$ & 20 & 7.1 & 20 \\
\hline & $\mathrm{K}$ & 39 & 28 & 47 \\
\hline & $\mathrm{Fe}$ & 6 & 4.6 & 2 \\
\hline & $\mathrm{Si}$ & 35 & 7.7 & 6 \\
\hline & $\mathrm{Ca}$ & 3 & 1.8 & 5 \\
\hline & $\mathrm{MgO}$ & 550 & - & - \\
\hline
\end{tabular}

a Data obtained from the supplier. ${ }^{37}$

pied by $\mathrm{Mg}^{2+}$ ions. ${ }^{22}$ This is cation antisite reaction and is known as inversion to describe departure from normal spinel structure. ${ }^{23,24}$ Considering that there are two potential cation sites in the spinel structure the following pairs of charged defects may form $\left(V_{\mathrm{Mg}}^{\prime \prime}, \mathrm{Al}^{\bullet} \mathrm{Mg}\right)$ and/or $\left(V_{\mathrm{Al}}^{\prime \prime \prime}, \mathrm{Al}{ }^{\bullet} \mathrm{Mg}\right)$. Diffusion in this case is easier due to the large concentration of lattice defects.

Apart from that, the microstructural development between $\mathrm{MgAl}_{2} \mathrm{O}_{4}$ and $\mathrm{Al}_{2} \mathrm{O}_{3}$ is studied with special attention to the microstructurally distinct interlayer which grows without a compositional discontinuity from parent spinel in the interface between the end-members. This study follows another study done by the authors on different bi-material oxide systems (alumina-zirconia and alumina-spinel) aimed at investigating the mechanical and chemical aspects ${ }^{25}$ and other detailed studies on sintering of spinel powder. ${ }^{26}$

\section{Experimental procedure}

Two different commercially available submicron-grained alumina powders were used in this study. The first powder, coded alumina $\mathrm{A}$, was an $\mathrm{MgO}$ doped Baikowski product (Batch $\mathrm{n}^{\circ}$ 660J CR 15 MgO-doped, Baikowski) while the second powder was a non-doped $\alpha$-alumina, coded alumina B, powder (Batch $\mathrm{n}^{\circ} 14406$ BMA15, Baikowski). Spinel $\left(\mathrm{MgAl}_{2} \mathrm{O}_{4}\right)$ powder was also a Baikowski product (S30-CR, Baikowski). Some physical, and chemical properties of the powders used in this study are shown in Table 1.

In order to achieve a good bond between alumina and spinel the interface development must be understood very well. Hence, three different sets of tests were planned. The first involved co-sintering of alumina-spinel pairs of co-pressed pellets. The second set was performed to see if two co-sintering steps would influence the interface layer microstructure. The third one was run to collect complementary information about the interface layer which develops between predensified alumina and spinel samples during the diffusion couple test.

The green bi-material cylindrical samples ( $8 \mathrm{~mm}$ diameter) were previously produced at low pressures of 50 or $100 \mathrm{MPa}$ with single-action (UP) or floating die (UPFlo) mode of uniaxial pressing. The first powder was poured into die cavity and was settled down by tapping with a metal rod before the second powder was added and co-pressed together. Then they were compacted under cold isostatic pressure at $250 \mathrm{MPa}$. Prepared green compacts of bi-materials were sintered in a vertical dilatometer (DHT2050K, Setaram, France) at $1400^{\circ} \mathrm{C}$ and $1500^{\circ} \mathrm{C}$ for $1-16 \mathrm{~h}$ with $3.3^{\circ} \mathrm{C} / \mathrm{min}$ of heating rate. This way, co-densification behaviors of the compacts were investigated. The sintered samples were cooled in furnace with $30^{\circ} \mathrm{C} / \mathrm{min}$ cooling rate.

In order to investigate the microstructures of the interface and components of the bi-materials after co-sintering, sintered pellets were cut parallel to the cylinder axis into two parts. Half of them were mounted into polyester resin before being ground and polished by conventional sample preparation methods. To reveal the morphology and microstructural alteration at the interface, bi-materials were thermally etched at about $100^{\circ} \mathrm{C}$ below the sintering temperatures. Microstructures of the polished and thermally etched surfaces were observed by SEM (scanning electron microscope, Zeiss, Ultra 55). Chemical etching with hot orthophosphoric acid was also done for some samples.

Co-pressed alumina and spinel compacts were sintered in two isothermal steps to understand the nucleation step of the columnar grain structure and the evolution of microstructures in the interface. Co-pressed samples were heated up to $1400^{\circ} \mathrm{C}$ for $4-16 \mathrm{~h}$ with $3.3^{\circ} \mathrm{C} / \mathrm{min}$ of heating rate followed by another heating step at $1500^{\circ} \mathrm{C}$ for $4-16 \mathrm{~h}$.

In addition to co-sintering process, to understand and determine more clearly the diffusion mechanisms between alumina and spinel pellets during co-sintering, diffusion couple of predensified spinel and alumina samples were tested. In a first step green compacts of alumina $\mathrm{A}$ and spinel were separately sintered at $1500^{\circ} \mathrm{C}$ for $30 \mathrm{~min}$ and $4 \mathrm{~h}$, respectively. Soaking times were so selected to achieve matching fired densities at $95 \%$ of theoretical density. Theoretical densities for spinel and alumina were taken as 3.55 and $3.987 \mathrm{~g} / \mathrm{cm}^{3}$, respectively. Therefore both alumina A and spinel end-members were predensified to $95 \%$ density before the diffusion couple test. The purpose was to leave some room for further densification when the two pellets were in contact during heating. Another reason was to use pores as markers for future observation. ${ }^{12}$ Cylindrical sintered samples were cut in two pieces from the centers of the pellets horizontally and then each of the cut surfaces was ground and well polished with $1 \mu \mathrm{m}$ diamond.

In the diffusion couple test predensified pellets of alumina and spinel were placed face to face to bring polished surfaces 

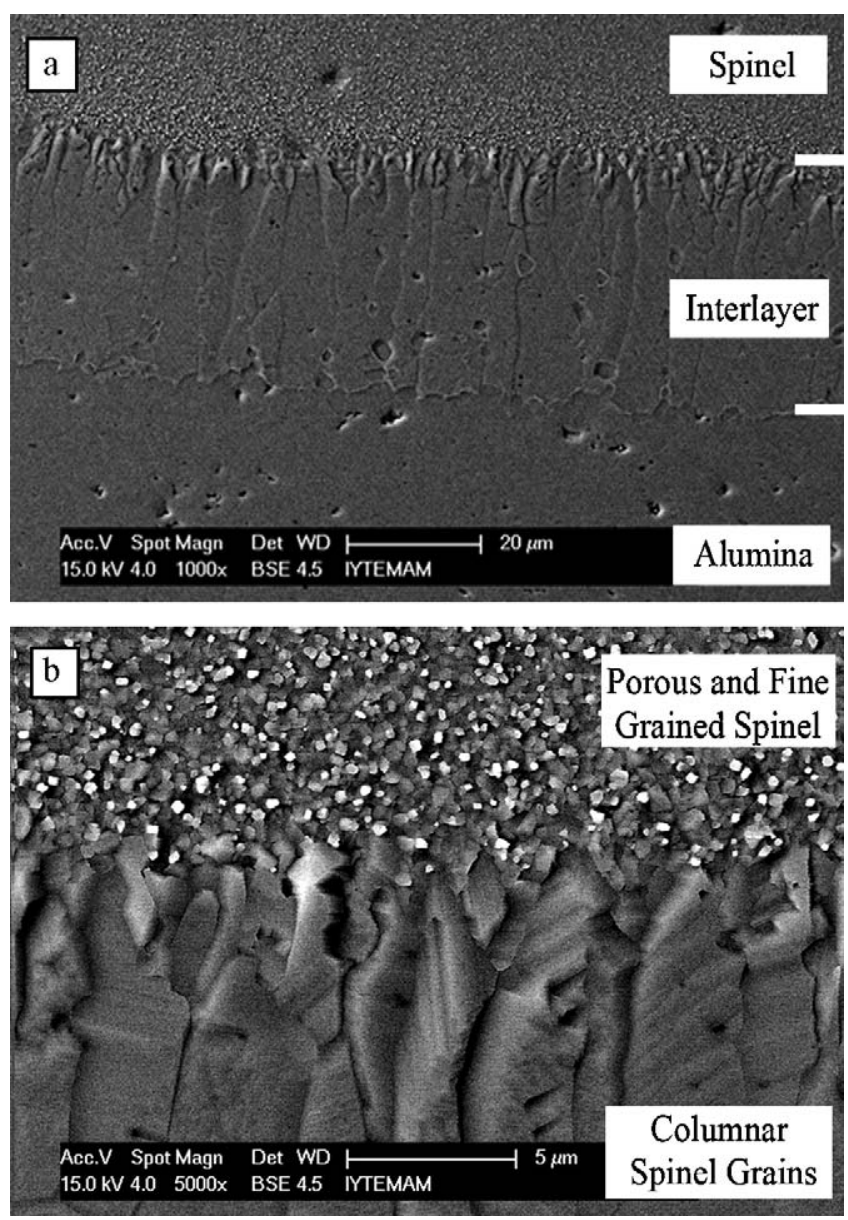

Fig. 2. Interface microstructure of spinel-alumina A bi-material co-sintered for $16 \mathrm{~h}$ at $1500^{\circ} \mathrm{C}$ (a) general view (b) a closer view of the porous and fine grained parent spinel and in situ grown columnar grained spinel.

in contact. In order to increase the contact and to decrease the diffusion gap between the end-members an external pressure (300 g 0.1 MPa) was applied. Diffusion couple tests were done in the dilatometer. This way, co-densification behaviors of the couples were investigated. The couple was heated up to $1500{ }^{\circ} \mathrm{C}$ for $16 \mathrm{~h}$ with $3.3^{\circ} \mathrm{C} / \mathrm{min}$ of heating rate.

\section{Results}

\subsection{Co-sintering at high temperature of co-pressed green compacts}

Alumina A and spinel co-pressed green compact was cosintered up to $1500^{\circ} \mathrm{C}$ at a heating rate of $3.3^{\circ} \mathrm{C} / \mathrm{min}$ for $16 \mathrm{~h}$. An interlayer composed of new generation columnar spinel grains was observed to form between the alumina and spinel (Fig. 2). The length of these columnar spinel grains was about $40 \mu \mathrm{m}$ depending on the sintering regime $\left(1500^{\circ} \mathrm{C}\right.$ for $16 \mathrm{~h}$ soaking $)$. These new spinel grains were elongated in this layer in contrast to the equiaxed grains in the neighboring spinel and alumina. When spinel starts to densify from green state, a fine spinel $(d \sim 400 \mathrm{~nm})$ region was observed in the parent spinel near the in situ columnar spinel grains as shown in Fig. 2(b). The thick- ness of fine and porous spinel region $(\sim 200 \mu \mathrm{m}$ in this case) was much higher than the length of columnar spinel grains $(\sim 40 \mu \mathrm{m})$. The amount of porosity in the middle of this porous region was measured to be $8 \%$ on chemically etched samples by image analysis methods. This porosity decreased to less than $2 \%$ at $300 \mu \mathrm{m}$ away from the interface and to $<1 \%$ at the body center of the spinel pellet. Size of the spinel grains far away from the columnar spinel grains and in the center of the spinel body was roughly about $800 \mathrm{~nm}$. On the other hand, grain size of the spinel closer to the external surface was nearly $3000 \mathrm{~nm}$ probably due to evaporation of $\mathrm{Mg}$ and resultant formation of excess $\mathrm{O}^{2-}$ vacancies in the spinel grains of the external surface region. ${ }^{27}$ This will be further discussed below. The microstructural schematic of this bi-material (alumina A-spinel) co-sintered at $1500^{\circ} \mathrm{C}$ for $16 \mathrm{~h}$ is illustrated in Fig. 3. Grain sizes of alumina near the columnar spinel grains and in the center of the alumina part were $3400 \mathrm{~nm}$ (Fig. 3). The width of columnar spinel grains was less than $5 \mu \mathrm{m}$.

Quantitative chemical analysis of co-sintered bimaterial samples with special attention on the columnar spinel grains was performed on a SEM by wavelength dispersive spectrometer (WDS). The results are given in Fig. 4. According to the results, chemical composition of columnar spinel grains was slightly different from the parent spinel. There was a slight decrease in $\mathrm{Mg}$ $(0.5 \mathrm{wt} \%)$ and a slightly larger increase in $\mathrm{Al}(>0.5 \mathrm{wt} \%)$ concentrations from the parent spinel to alumina. Similar observations were reported in the literature. ${ }^{2,3}$ The concentration gradient along the columnar spinel grains was $0.0125 \% / \mu \mathrm{m}$ for both $\mathrm{Mg}$ and $\mathrm{Al}$. As shown in Fig. 3, another observation was that the concentrations of $\mathrm{Mg}$ in the columnar spinel region (13.5\%) and the porous spinel region $(\sim 14.0 \%)$ were lower than the stoichiometric amount of $16.9 \%$. Concentration profile for $\mathrm{Mg}$ or $\mathrm{Al}$ did not show a discontinuity through the porous parent spinel and columnar spinel grains. A WDS analysis farther into the spinel revealed that the $\mathrm{Mg}$ concentration was constantly increasing in moving away from the interface until the stoichiometric amount is reached well into the center of the spinel body. Similar behavior in the reverse direction was detected for Al. According to Schmalzried ${ }^{28}$ such concentration profiles could result from mixed transport interface control mechanisms and the growth of the columnar region is rate-limited by both dissolution reaction and chemical diffusion of reactants, the latter being more dominant.

Crystal orientation of columnar spinel grains was investigated by electron backscattered diffraction (EBSD) method. ${ }^{29}$ Alumina A and columnar spinel grains are demonstrated in Fig. 5. The color of each columnar grain in Fig. 5(b) corresponds to the crystallographic orientation of its elongation axis (inverse pole figure transverse direction); blue, green and red grains have their elongation axis parallel to respectively $\left\langle\begin{array}{llll}1 & 1 & 1 & 1\end{array},\left\langle\begin{array}{lll}1 & 0 & 1\end{array}\right\rangle\right.$ and $\langle 001\rangle$ type directions. According to the results, each columnar grain shows different color which means that they have the same cubic crystal structure with relatively random crystallographic orientations as observed on the (001) stereographic projection (Fig. 5(b)). This is due to the nucleation of these columnar grains from the spinel part that consisted of randomly oriented equiaxed fine grains. Formation and growth of columnar spinel grains are thought to proceed as follows. First, new generation of spinel 


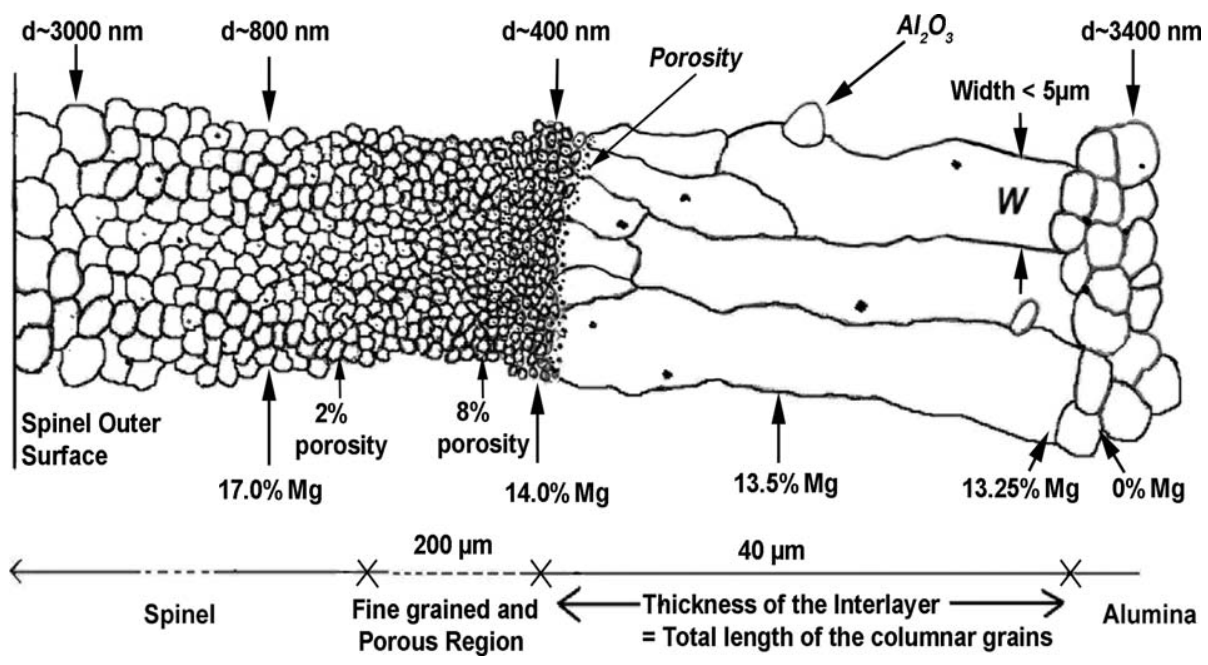

Fig. 3. Schematic illustration of bi-material (alumina A-spinel) microstructure co-sintered $16 \mathrm{~h}$ at $1500^{\circ} \mathrm{C}$.

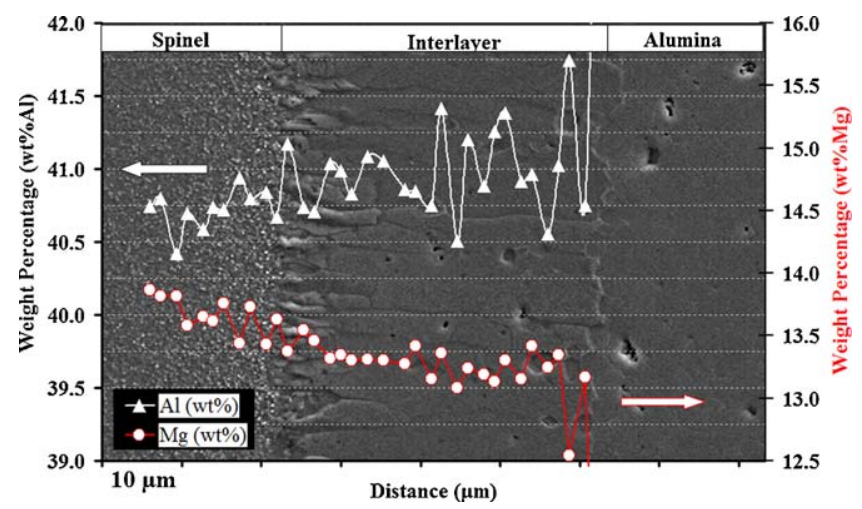

Fig. 4. WDS analysis of the interlayer between spinel and alumina. Mg concentration slightly decreases from left to right. Al concentration increases in the same direction. Alumina A-spinel co-sintered samples (at $1500{ }^{\circ} \mathrm{C}$ for $16 \mathrm{~h}$ ).

forms at the spinel-alumina interface by dissolution of $\mathrm{Al}^{3+}$ ions in the spinel lattice to produce a grossly non-stoichiometric Alrich spinel. Because the spinel grains are randomly oriented and provide the nuclei for formation of the columnar spinel grains, the initial set of these columnar spinel grains grow randomly into alumina along the concentration gradient of $\mathrm{Mg}$ and $\mathrm{Al}$. After some growth, these new in situ formed spinel grains compete with each other and those favorably oriented grains grow faster and wider. According to Kotula ${ }^{30}$ and Schmalzried ${ }^{28}$ the growth of spinel on alumina is dependent on crystallographic orientation of corundum. For example, it was observed to be lower on the basal plane with larger density of oxygen ions compared to other planes. The less fortunate grains that are oriented sideways fade out as they cannot be supplied with sufficient $\mathrm{Mg}$ due to excessively long distances for diffusion.

The amount of porosity in spinel was observed to decrease from the interface to the bulk of the spinel. Maximum porosity was present in the interface between parent spinel and columnar spinel grains. Spinel grain size evolution was followed with SEM in the bi-material alumina B-spinel which was sintered at $1500{ }^{\circ} \mathrm{C}$ for 16 h. Fig. 6 shows the increasing spinel grain size from the interface to the interior of spinel. In the same direc- tion, pores almost completely disappeared $90 \mu \mathrm{m}$ away from the interface (Fig. 6(c)). Nearly $360 \mu \mathrm{m}$ away from the interface, the grain size roughly became two times bigger than that near the interface (Fig. 6(d)).

The grain size profiles from interface to interior of spinel for each type of bi-material are given in Fig. 7. Both co-sintered bimaterials have nearly the same grain size at the center of spinel part but they have slightly different grain sizes near the interface.

A question came up then if grain growth, pore closure or new grain formation occurred during thermal etching, thereby leading to biased results. Chemical etching with orthophosphoric acid at $140{ }^{\circ} \mathrm{C}$ was performed to verify data in Figs. 6 and 7 . The same trend in grain sizes was observed on the samples that were chemically etched with slightly smaller grain size measurements. Chemical etching also revealed that porosity in parent spinel was higher than that observed in Fig. 6. Some porosity values are indicated in Fig. 3.

The effects of pressing method, sintering temperature, soaking time, and type of alumina (550 ppm magnesium-doped or non-doped) on the spinel columnar grains interlayer thickness of spinel-alumina co-sintered bi-materials were evaluated. The results of all the columnar spinel grain lengths are given in Fig. 8. The co-pressed bi-materials were co-sintered at $1400{ }^{\circ} \mathrm{C}$ or $1500{ }^{\circ} \mathrm{C}$ with $3.3^{\circ} \mathrm{C} / \mathrm{min}$ heating rate for different soak times. The columnar spinel grain lengths are found to be directly proportional to the square root of soaking time. These results are in reasonable agreement with a parabolic diffusion equation (3). The main effect was obtained from the soaking temperature. Other factors were not significantly effective. Type of alumina (whether doped with $\mathrm{MgO}$ or not) was found not to have a significant effect on the extent of the formation of columnar spinel grain layer. $^{25}$

Assuming that the growth of columnar spinel grains could be controlled by a diffusion mechanism, experimental apparent diffusion coefficients $(D)$ of columnar grained spinel layer were calculated by using average length versus square root of soak time results of bi-materials according to equation

$x=k \sqrt{D t}$ 

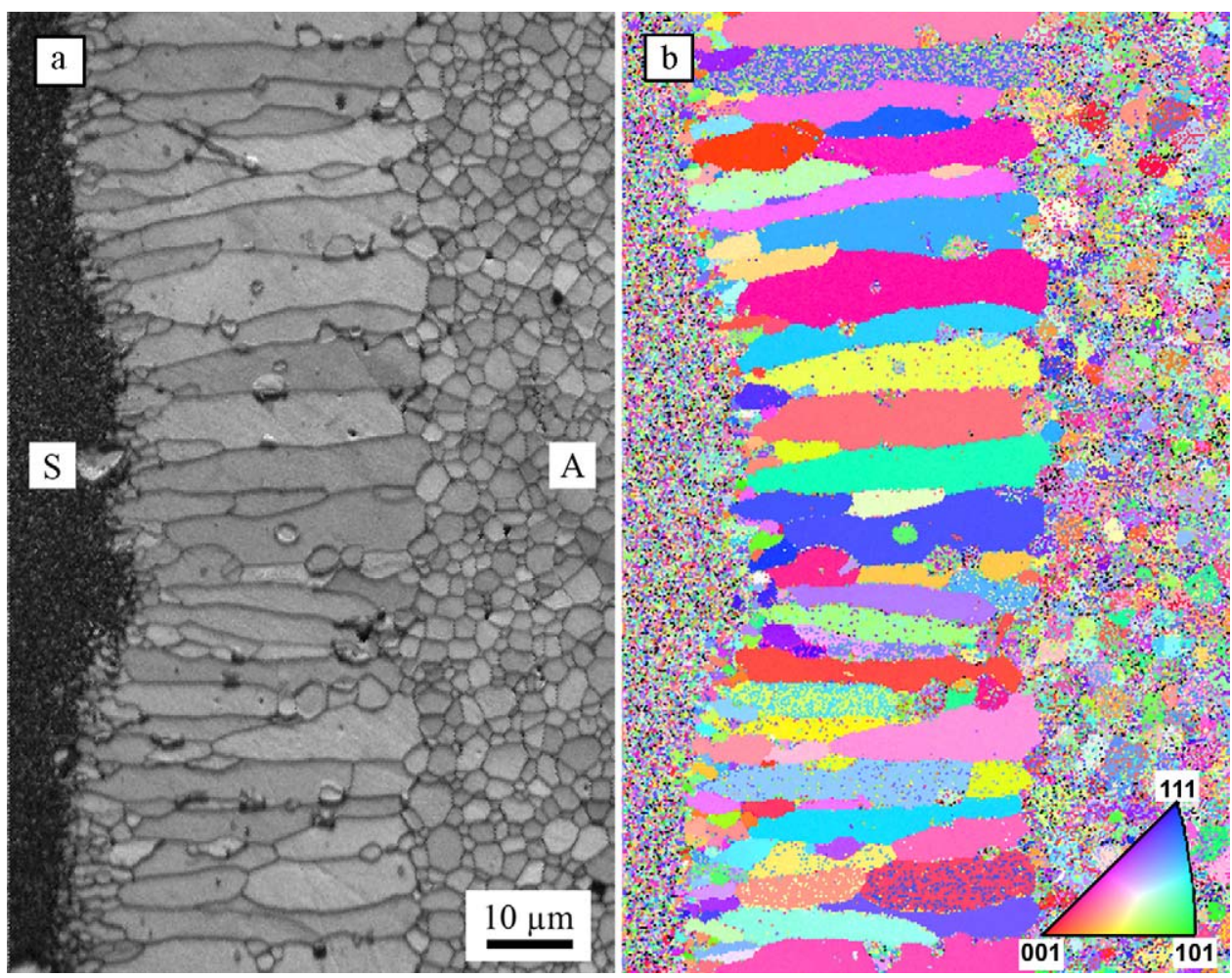

Fig. 5. Microstructure and random crystallographic orientation of spinel columnar grains growing during co-sintering at $1550^{\circ} \mathrm{C}$ for $16 \mathrm{~h}$ of alumina A-spinel bi-materials (a) secondary electron SEM image (b) inverse pole figure transverse direction = along the grain elongation with color coded map. (For interpretation of the references to color in this figure legend, the reader is referred to the web version of the article.)
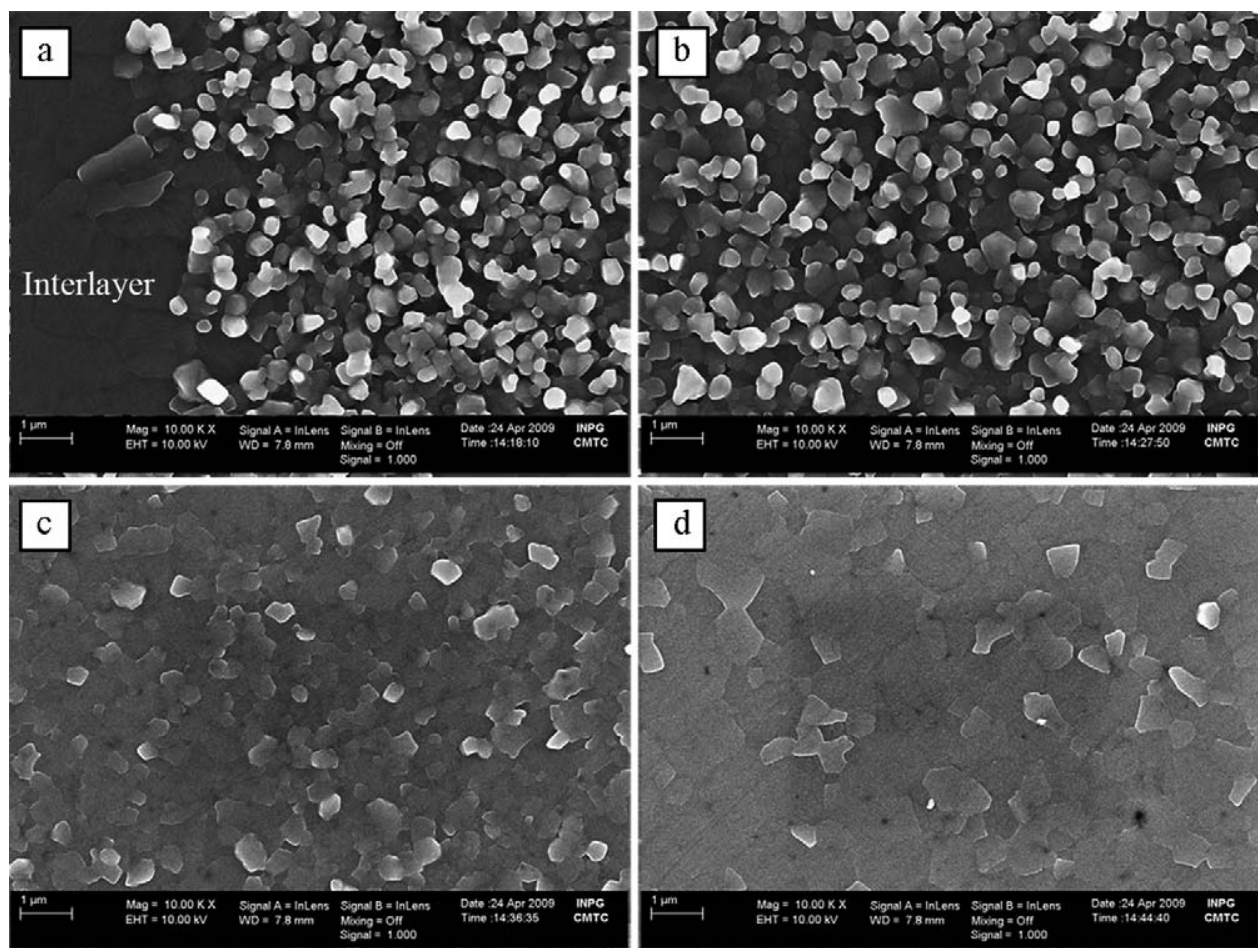

Fig. 6. Porous region in parent spinel end-member in alumina B-spinel bi-material (a) near the interlayer, (b) $40 \mu \mathrm{m}$, (c) $90 \mu \mathrm{m}$, and (d) $360 \mu \mathrm{m}$ away from the interlayer into bulk of the parent spinel. The bi-material was sintered at $1500^{\circ} \mathrm{C}$ for $16 \mathrm{~h}$ with $3.3^{\circ} \mathrm{C} / \mathrm{min}$ heating rate. 


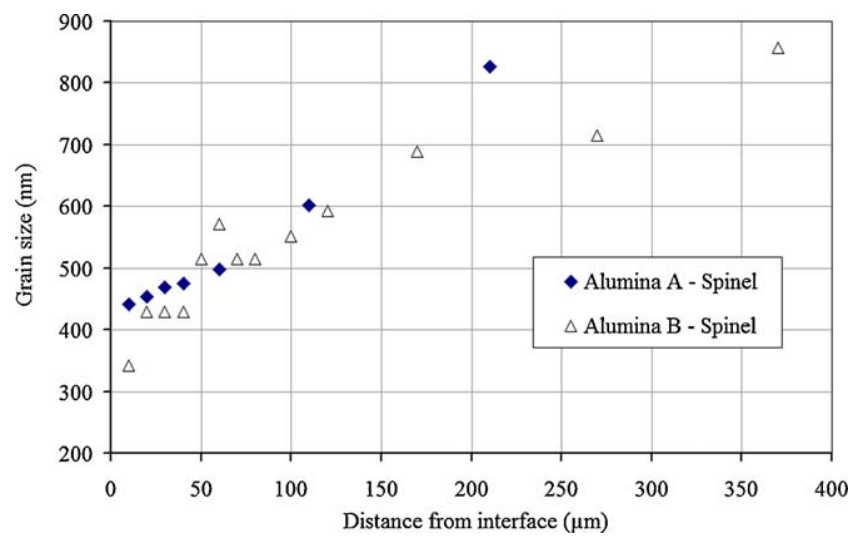

Fig. 7. Spinel grain size profiles from interface to interior of spinel for each type of co-sintered bi-material for $16 \mathrm{~h}$ at $1500^{\circ} \mathrm{C}$. Polished cross sections were thermally etched at $1450^{\circ} \mathrm{C}$ for $30 \mathrm{~min}$.

$x$, thickness of spinel columnar grained interlayer $(\mu \mathrm{m}) ; t$, soaking time at specified temperature (h); $D$, apparent diffusion coefficient.

Calculated activation energy for growth of columnar spinel grain and corresponding apparent diffusion coefficients of bimaterials are tabulated in Table 2. As a result of calculations, the apparent activation energies $(Q)$ of alumina A-spinel and alumina B-spinel were 450 and $425 \mathrm{~kJ} / \mathrm{mol}$, respectively. And their apparent diffusion coefficients $(D)$ were $2.6 \times 10^{-14} \mathrm{~m}^{2} / \mathrm{s}$ and $2.2 \times 10^{-14} \mathrm{~m}^{2} / \mathrm{s}$ at $1500^{\circ} \mathrm{C}$.

In the spinel literature, several scientists reported values of the diffusion coefficients $\left(D_{\mathrm{o}}\right)$ of $\mathrm{Al}^{3+}, \mathrm{Mg}^{2+}$ and $\mathrm{O}^{2-}$ ions. Reimanis and Kleebe ${ }^{31}$ tabulated the diffusion coefficients and related the activation energy results. When compared with the literature, ${ }^{31}$ lattice $\mathrm{O}^{2-}$ ion diffusion could be the limiting diffusion mechanism of growth of the spinel columnar grains because of its low diffusion coefficient, limiting the diffusion process. As $\mathrm{Mg}^{2+}$ diffuse much faster than $\mathrm{O}^{2-}$ ion, the solid state chemical reaction (1) at the end of spinel columnar grains on the alumina side appears to be limited by the $\mathrm{O}^{2-}$ ion bulk diffusion. According to Schmalzried ${ }^{11}$ the diffusion rate of $\mathrm{O}^{2-}$ is much smaller than that of the cations so it can perhaps be regarded as relatively stationary.

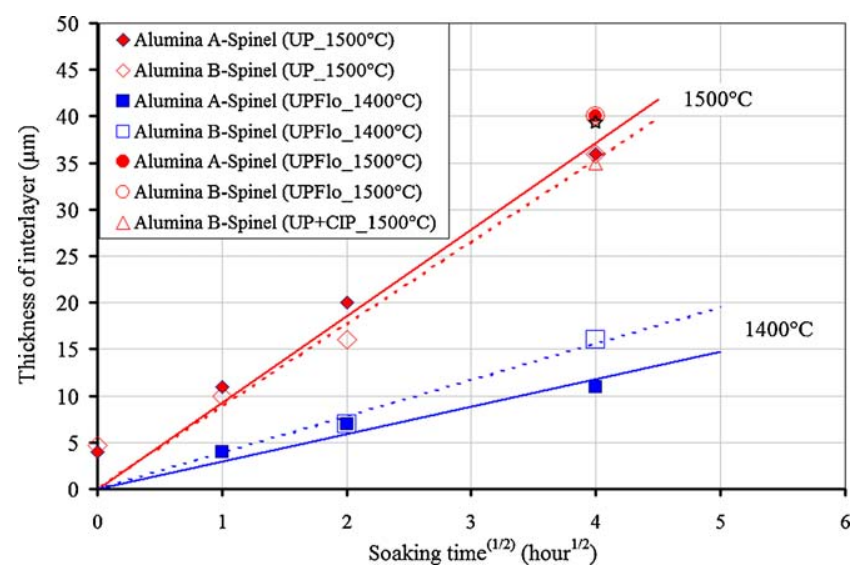

Fig. 8. Effect of soaking time, pressing method and temperature on the interlayer thickness of alumina-spinel co-sintered bi-materials. Star indicates a spinel interlayer of columnar grains in alumina A-spinel diffusion couple test.

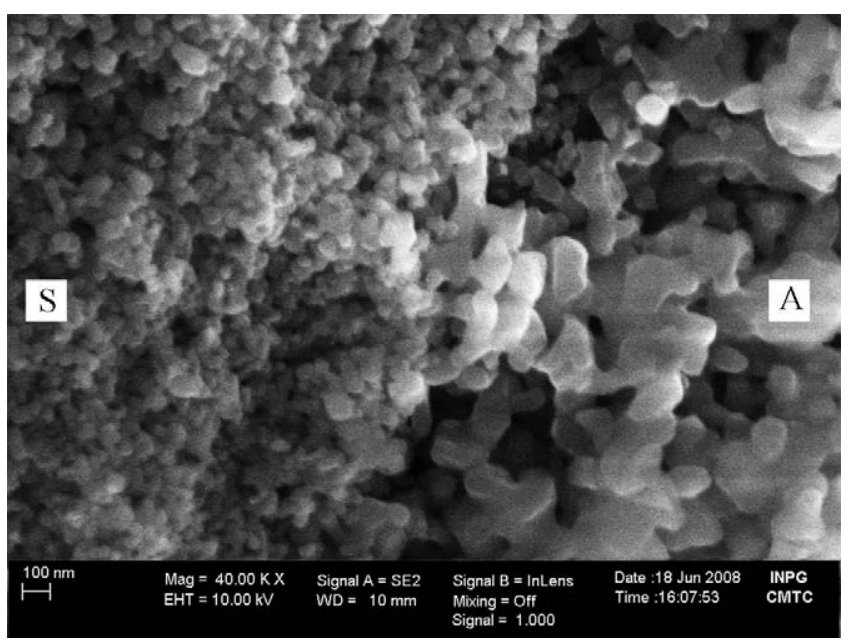

Fig. 9. SEM image of the fracture surface of alumina-spinel bi-material cosintered at $1150^{\circ} \mathrm{C}$ for $16 \mathrm{~h}$. A, alumina; S, spinel.

Columnar spinel grains are thought to nucleate from initial fine spinel grains and to grow towards alumina. Evidence for this proposition can be seen in Figs. 2(a), 4 and 5(a) where the phase boundaries between columnar spinel grains and alumina are almost always curved with their centers of curvature in alumina grains. As these images were taken after $16 \mathrm{~h}$ of soak period at $1500{ }^{\circ} \mathrm{C}$, further soak at this temperature is expected to advance the boundary or interface into alumina. Therefore, the columnar spinel grains grow into alumina away from spinel. Further evidence for this argument will be presented in Section 3.4. A dissolution of alumina grains in spinel phase at the end of spinel columnar grains can be also considered as an interface reaction; the kinetic of such interface reaction should not be excluded as a possible contribution to the control of the growing kinetic of spinel columnar grains. ${ }^{28}$

\subsection{Initial stage of co-sintering of bi-material at low temperature}

The formation of columnar spinel grains, extent of sintering, and adhesion mechanisms were investigated at very low temperatures. Fig. 9 depicts the alumina-spinel bi-material fracture surface. The left side of the image is the alumina part. The sample was co-sintered at $1150{ }^{\circ} \mathrm{C}$ for $16 \mathrm{~h}$. Maximum shrinkage of the bi-material was about $8 \%$ and its components of alumina and spinel have also individually nearly the same shrinkage values as their bi-material. ${ }^{25}$ The grain sizes of alumina and spinel were $200 \mathrm{~nm}$ and $80 \mathrm{~nm}$, respectively. Thus the grain size of both materials almost doubled. The diffusion rate is also low between the components, but some necking contact between alumina and spinel can still be partially established as shown in Fig. 9.

\subsection{Co-sintering of green compacts by two isothermal steps sintering}

The next set of experiments was done to determine if two isothermal steps co-sintering would lead to a different interlayer microstructure. The two sintering steps were done at $1400^{\circ} \mathrm{C}$ 
Table 2

Experimental diffusion coefficients and apparent activation energies deduced from the growth kinetics of the columnar grained spinel during bi-material co-sintering.

\begin{tabular}{|c|c|c|c|}
\hline \multirow[t]{2}{*}{ Type of bi-materials } & \multicolumn{2}{|c|}{$\begin{array}{l}\text { Apparent diffusion coefficients of } \\
\text { bi-materials at temperature }\end{array}$} & \multirow[t]{2}{*}{$\begin{array}{l}\text { Apparent activation energy of } \\
\text { interlayer growth }(\mathrm{kJ} / \mathrm{mol})\end{array}$} \\
\hline & $1400^{\circ} \mathrm{C}$ & $1500^{\circ} \mathrm{C}$ & \\
\hline Alumina B-spinel & $4.0 \times 10^{-15}$ & $2.2 \times 10^{-14}$ & 425 \\
\hline
\end{tabular}

for $16 \mathrm{~h}$ followed by another sintering at $1500^{\circ} \mathrm{C}$ for $16 \mathrm{~h}$. SEM micrograph of the sample is given in Fig. 10. Interestingly, the columnar spinel grains were found to consist of two separate easily distinguishable areas. On the left of Fig. 10, a band of first generation columnar spinel interlayer was observed. Same observation was made on chemically etched samples. Total length of the columnar spinel grains was nearly $5 \mu \mathrm{m}$ after the first isothermal step $\left(1400^{\circ} \mathrm{C}\right)$ and was $40 \mu \mathrm{m}$ after the second isothermal step $\left(1500^{\circ} \mathrm{C}\right)$ sintering. A thin porous layer is observed in the spinel part just near the interface; this porous layer is much less extended than in the case of the samples co-sintered directly at $1500^{\circ} \mathrm{C}$.

\subsection{Diffusion couple test}

The test was done to confirm the direction of diffusion and to understand the formation of columnar spinel grains from predensified ceramics. Diffusion couple test was done as mentioned in Section 2. At the end of the test, weak adhesion was observed between the two end-members which were easily separated by hand.

Contact surface of the alumina end-member was analyzed by XRD to determine the crystal phases. These results, which are not given here for the sake of brevity, further confirmed the EDS results that alumina rich spinel phase $\left(\mathrm{Mg}_{0.734} \mathrm{Al}_{2.177} \mathrm{O}_{4}\right)$ formed on the surface of the alumina end-members. More experimental details about this paper can be seen in Ref. [26].

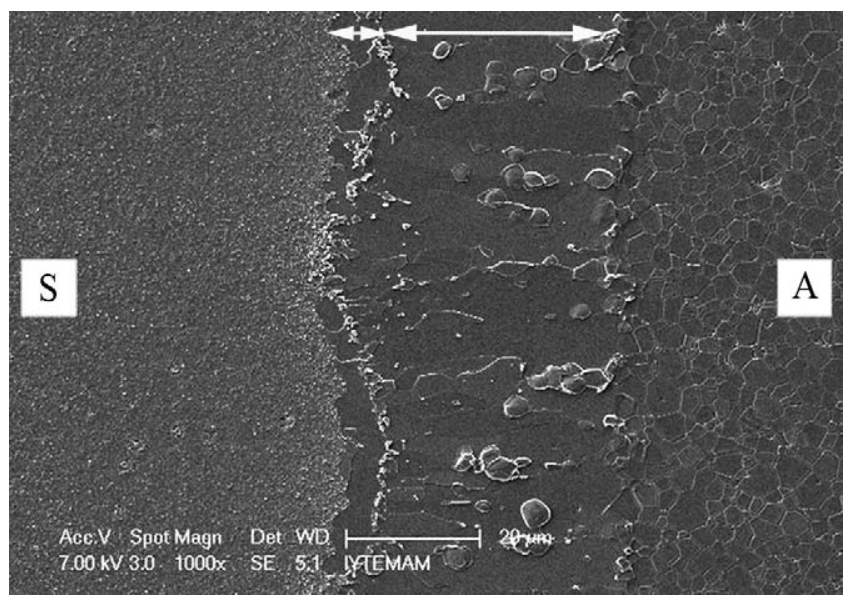

Fig. 10. SEM image of alumina A-spinel bi-material interlayer after two isothermal steps co-sintering $\left(16 \mathrm{~h}\right.$ at $1400^{\circ} \mathrm{C}+16 \mathrm{~h}$ at $\left.1500^{\circ} \mathrm{C}\right)$. Interlayer consists of a $5 \mu \mathrm{m}$ long spinel layer on the left and a longer columnar grained spinel on the right. S, parent spinel; A, alumina.
Fig. 11(a) and (b) shows the columnar spinel grains that grew into the alumina end member. Widths of the columnar spinel grains were smaller than $5 \mu \mathrm{m}$ in co-sintered samples (Fig. 2) while they were larger than $8 \mu \mathrm{m}$ when predensified pellets were contacted and heated (Fig. 11). The increase in the width of the columnar grains can be attributed to the smaller number of nucleating sites for spinel in predensified samples as opposed to the green pellets which obviously had smaller crystallites $(55 \mathrm{~nm})$ than the predensified spinel end-member of which the grain size was about $540 \mathrm{~nm}$. Total length of the columnar spinel grains was about $40 \mu \mathrm{m}$ (Fig. 11(a)). This value was more or less the same in all bi-materials after the same thermal treatment
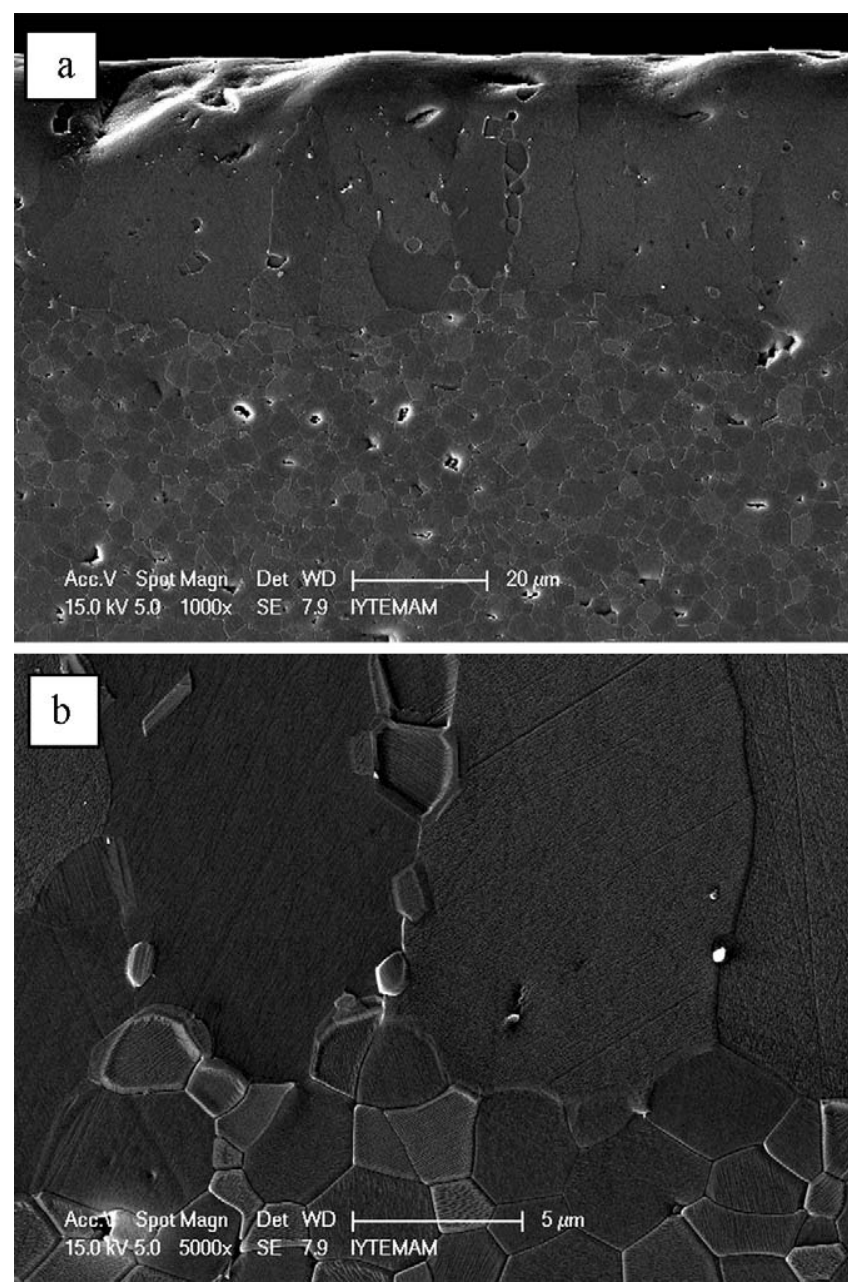

Fig. 11. Columnar spinel grains growing into the alumina end-member of spinel-alumina diffusion couple (at $1500^{\circ} \mathrm{C}$ for $16 \mathrm{~h}$ ). SEM images of polished and thermally etched cross section of predensified alumina end-member at different magnifications. 
$\left(1500^{\circ} \mathrm{C} 16 \mathrm{~h}\right)$ independently of the initial densities of each bimaterial parts (Fig. 8). This evidence also proved that the same mechanisms (diffusion inside the columnar spinel grains and possible interface reaction at the end of columnar spinel grains) are limiting the growth and the kinetics of growth of these columnar spinel grains. Fig. 11(b) shows that the phase boundaries between spinel and alumina are almost always curved with the center of curvature in alumina grains which indicates that interphase boundaries tend to migrate into alumina. It was found that the width of the columnar spinel grains in the interlayer was small near the spinel interface and widened closer to alumina.

These observations and their analyses mainly show that an interface layer of columnar spinel grains grows during the high temperature thermal cycle at the expense of the alumina body. The thickness of the layer of these columnar spinel grains is not significantly dependent on the initial densities of spinel and alumina end-members (co-sintered bi-materials or diffusion couple of predensified materials). The kinetics of growth of this interface layer can be mainly quantified by a classical parabolic equation with an apparent activation energy of about $425-450 \mathrm{~kJ} / \mathrm{mol}$ in the $1400-1500^{\circ} \mathrm{C}$ temperature range. This apparent activation energy and corresponding diffusion coefficients correspond well with the parameters of oxygen diffusion in spinel lattice (volume diffusion) reported in the literature. ${ }^{31}$ On the other hand, there are many mechanisms which may interact and it is difficult to separate one controlling mechanism. Quantification of apparent activation energy in this study has no direct connection with one mechanism.

\section{General interpretation and discussion}

A good mechanical bond can be formed between spinel and alumina in co-sintered samples. Microstructural analysis of the interface revealed that a spinel interlayer of columnar grains forms between alumina and spinel regardless of the type of test. Widths of these columnar grains were less than $5 \mu \mathrm{m}$ in co-sintered samples. In our configuration (alumina-spinel bi-materials) diffusion of $\mathrm{Mg}^{2+}$ and $\mathrm{O}^{2-}$ ions necessarily occurs from parent stoichiometric spinel through the nonstoichiometric columnar grained spinel until they reach the reaction interface to meet corundum. So the kinetics of growth of these columnar grains can be controlled by diffusion of $\mathrm{Mg}^{2+}$ and $\mathrm{O}^{2-}$ ions and by the interface reaction of dissolution of alumina in alumina-rich spinel. Results of this study suggested that the kinetic is mainly controlled by diffusion without quantitative evidence of a possible interface reaction kinetic contribution. Schmalzried ${ }^{11}$ proposed that $\mathrm{O}^{2-}$ ion diffusion is much slower than cation diffusion in periclase-corundum diffusion couples. In this study, however, only spinel and alumina are in contact and hence the diffusion of $\mathrm{Mg}^{2+}$ and $\mathrm{O}^{2-}$ to the reaction site is probably also rate limiting.

Spinel grain size and porosity were found to vary depending on the location in the spinel part of co-sintered samples and on the sintering temperature. At high temperature the equilibrium vapor pressure of magnesium increases rapidly; the vapor pressure of $\mathrm{Mg}$ is 10 times larger at $1500^{\circ} \mathrm{C}$ than at $1400^{\circ} \mathrm{C} .{ }^{32}$ Carter and separately Navias were able to grow a spinel layer on alumina through vapor transport of $\mathrm{Mg} .{ }^{12,16}$ Hallstedt, ${ }^{33}$ and especially Sasamoto et al. ${ }^{32}$ and Altman, ${ }^{34}$ reported on the vapor pressure of $\mathrm{Mg}$ over different $\mathrm{Mg}$ containing oxides. In the case of co-sintering experiments, before the spinel body completes densification and closes pores, evaporation of $\mathrm{Mg}$ from fine spinel grains, fast vapor diffusion in interconnected pore channels on rather long distances and condensation at the interface are also expected in addition to the transport of $\mathrm{Mg}$ by solid state diffusion. Such mechanisms can explain the gradient of spinel grain size and porosity in co-sintered samples from the interface towards the center of spinel part. The evolution of the microstructure (grain size and porosity) in the final-stage sintering of spinel with a gradient of magnesium content appears very complicated and depends on various parameters as shown by Ting and Lu. ${ }^{27}$ The thin layer of porosity observed in the spinel part of co-sintered samples in two steps (Fig. 10) can be considered as a Kirkendall effect ${ }^{8}$ due to the solid state diffusion of magnesium from spinel part towards the alumina part during the $16 \mathrm{~h}$ soak at $1500^{\circ} \mathrm{C}$. In the case of single step co-sintering at $1500^{\circ} \mathrm{C}$, this "classical" Kirkendall effect is hidden by the long distance diffusion of magnesium vapor in interconnected pore channels which leads to the grain size and porosity gradients in the spinel end-member.

In diffusion couple test the same columnar spinel interlayer formed into alumina end-member at its contact points with the spinel end-member where $\mathrm{Mg}^{2+}$ was found to rapidly diffuse into alumina. On the other hand, $\mathrm{O}^{2-}$ diffusion into alumina is considerably slower, as confirmed by the activation energy calculations, thus $\mathrm{O}^{2-}$ diffusion through the spinel interlayer appears to control the kinetics of interlayer growth. Similar conclusions were stated by Bratton ${ }^{35}$ and Ting. ${ }^{20}$ Widths of the columnar grains were more than $8 \mu \mathrm{m}$ in the diffusion couple test of predensified end-members. It is thought that smaller columnar grain width of $5 \mu \mathrm{m}$ in co-sintered samples was due to larger number of initial nucleation sites offered by green spinel end-member for growth of the interlayer.

Columnar grains are so formed probably due to concentration gradient of $\mathrm{Mg}^{2+}$ and $\mathrm{O}^{2-}$ between the end-members. They are thought to nucleate on the surface of spinel and grow into alumina. When single crystal alumina is brought into a high temperature contact with single crystal of $\mathrm{MgO}$, on the other hand, the interlayer grows in both directions. ${ }^{1,2}$ When the temperature is increased, the columnar grains will grow longer due to improved diffusion kinetics. ${ }^{25}$ The diffusion mechanism for columnar grain growth is reported to be due to volume (also called lattice diffusion) diffusion, ${ }^{2}$ and the faster vapor transport of magnesium is not the controlling kinetic mechanism because columnar grains extend almost all the way through the interlayer.

Columnar grains grow in an opposite direction to spinel, down the concentration gradient for $\mathrm{Mg}^{2+}$. Their lengths are almost equal to the thickness of the interlayer which varies parabolically with time thus suggesting a diffusion controlled process. It was proposed that the reaction rate (thickness of interlayer) was independent of crystallographic orientation of parent oxides. ${ }^{1}$ However, columnar grains are observed to slightly decrease in number as they move away from spinel, indicating some coalescence of grains. 
Kotula studied the growth of $\mathrm{NiAl}_{2} \mathrm{O}_{4}$ on $\mathrm{Al}_{2} \mathrm{O}_{3}$ single crystals of different crystallographic orientations. ${ }^{30}$ Schmalzried further discussed this paper and proposed that the rate of growth of spinel layer is smaller the higher the oxygen ion concentration in the $h \mathrm{kl}$ plane of corundum crystal. He further suggested that there is counterdiffusion of cations across the $\mathrm{NiAl}_{2} \mathrm{O}_{4} / \mathrm{Al}_{2} \mathrm{O}_{3}$ boundary and that the diffusion of $\mathrm{Ni}^{2+}$ ions is the rate determining step. ${ }^{28,36}$

Another study on spinel also showed the formation of columnar spinel grains that grew between new in situ formed equiaxed spinel grains and the corundum end-members. ${ }^{2,13}$ Thus columnar spinel grains in the interlayer phase appear to always grow between spinel and corundum.

Reactions at the interfaces between alumina and magnesia were studied by several researchers by using either single or polycrystalline components. ${ }^{1-3}$ Other relevant studies involved magnesia and spinel interfaces, ${ }^{15}$ interfaces between oxides like $\mathrm{NiO}-\mathrm{Al}_{2} \mathrm{O}_{3}{ }^{13}$ and $\mathrm{Y}_{2} \mathrm{O}_{3}-\mathrm{Fe}_{2} \mathrm{O}_{3} .{ }^{7}$ But no study was found in the literature regarding the reaction at the interface between polycrystalline alumina and polycrystalline spinel. Hence this study fills this gap in the literature.

When alumina and magnesia are heated in contact, they are observed to develop two distinct spinel interlayers. An equiaxed spinel forms on magnesia side and a thicker layer of columnar spinel forms on the alumina side. ${ }^{1,2}$ A question may arise as to how the interlayer would grow if a single crystal of alumina and a polycrystalline spinel were heated together. Based on the data collected in this study, the spinel interlayer is expected to form as polycrystalline columnar grains if a single crystal of alumina is brought into contact with polycrystalline spinel. This is a priori supported by data of Rossi and Fulrath ${ }^{1}$ as well as the data of Watson and Price. ${ }^{2}$ Another possible scenario is if polycrystalline alumina is contacted with single crystal of spinel at high temperature. In this case a single crystal interlayer of spinel is expected to form because the interlayer nucleates on the surface of spinel and grows into alumina. Direction of propagation of the interlayer was observed to occur into alumina both in this study and previously by Watson and Price. ${ }^{2}$

\section{Conclusions}

When alumina and spinel are co-sintered at $1500^{\circ} \mathrm{C}$, a good bond was observed to form between the two in the form of a new generation columnar spinel grains. A much weaker bond formed during the diffusion couple test at the same temperature but the same columnar spinel grains were observed although discontinuously. These columnar spinel grains nucleated from the original spinel-alumina interface and grew into alumina up to about $40 \mu \mathrm{m}$ after $16 \mathrm{~h}$ of sintering at $1500^{\circ} \mathrm{C}$. The growth of columnar grained spinel layer as a function of time was found to follow parabolic kinetics. Without quantitative evidence of a possible interface reaction kinetic contribution, lattice diffusion of $\mathrm{O}^{2-}$ ions in the columnar spinel grain layer is proposed as the main rate limiting processes. These columnar grains had widths of less than $5 \mu \mathrm{m}$ in co-sintered samples and more than $8 \mu \mathrm{m}$ in diffusion couple test. The center of curvature of the phase boundary between columnar spinel grains and alumina was always located in alumina, indicating that they were in the process of growing into alumina. As far as the mechanism for formation and growth of the columnar spinel grains, all two scenarios are thought to occur. These are volume diffusion inside the columnar grains and magnesium vapor transport inside the porous spinel part.

Two isothermal steps co-sintering was found to lead to the formation of columnar spinel grains with two distinct forms.

In diffusion couple test the same columnar spinel grains formed into alumina end member at its contact points with the spinel end-member where $\mathrm{Mg}^{2+}$ and $\mathrm{Al}^{3+}$ were found to rapidly counterdiffuse. This finding proved that the columnar spinel grains nucleated from the original spinel-alumina interface and proceeded to alumina. Another argument for the direction of propagation of the interlayer was the center of curvature of the phase boundary between columnar spinel grains and alumina end member to exist in the latter.

\section{Acknowledgements}

The authors are grateful to CMTC-Grenoble and IYTEMAM staff for their help and technical support and Baikowski for providing alumina and spinel powders.

\section{References}

1. Rossi RC, Fulrath RM. Epitaxial growth of spinel by reaction in the solid state. J Am Ceram Soc 1963;46:145-9.

2. Watson EB, Price JD. Kinetics of the reaction $\mathrm{MgO}+\mathrm{Al}_{2} \mathrm{O}_{3} \rightarrow \mathrm{MgAl}_{2} \mathrm{O}_{4}$ and $\mathrm{Al}-\mathrm{Mg}$ interdiffusion in spinel at 1200 to $2000^{\circ} \mathrm{C}$ and 1.0 to $4.0 \mathrm{GPa}$. Geochim Cosmochim Acta 2002;66(12):2123-38.

3. Zhang $\mathrm{P}$, Debroy $\mathrm{T}$, Seetharaman $\mathrm{S}$. Interdiffusion in the $\mathrm{MgO}-\mathrm{Al}_{2} \mathrm{O}_{3}$ spinel with or without some dopants. Metall Mater Trans A 1996;27(8):2105-14.

4. Sun L, Sneller A, Kwon P. Fabrication of alumina/zirconia functionally graded material: from optimization of processing parameters to phenomenological constitutive models. Mat Sci Eng A-Struct 2008;488(1-2):31-8.

5. Boonyongmaneerat $\mathrm{Y}$, Schuh CA. Contributions to the interfacial adhesion in Co-sintered bilayers. Metall Mater Trans A 2006;37A(5):1435-42.

6. Simchi A, Rota A, Imgrund P. An investigation on the sintering behavior of 316L and 17-4PH stainless steel powders for graded composites. Mat Sci Eng A-Struct 2006;424(1-2):282-9.

7. Buscaglia V, Caracciolo F, Bottino C, Leoni M, Nanni P. Reaction diffusion in the $\mathrm{Y}_{2} \mathrm{O}_{3}-\mathrm{Fe}_{2} \mathrm{O}_{3}$ system. Acta Mater $1997 ; \mathbf{4 5}(3): 1213-24$.

8. Smigelkas AD, Kirkendall EO. Zinc diffusion in alpha brass. AIME Trans 1947;171.

9. Siao CY, Lee HW, Lu HY. Kirkendall porosity in barium titanate-strontium titanate diffusion couple. Ceram Int 2009;35(7):2951-8.

10. Wagner C. Über den Mechanismus von doppelten Umsetzungen durch Reaktion im festen Zustand. Z Anorg Allg Chem 1938;236(320-338).

11. Schmalzried H. Chemical kinetics of solids. Weinheim: Verlag Chemie; 1995.

12. Carter RE. Mechanism of solid-state reaction between magnesium oxide and aluminium oxide and between magnesium oxide and ferric oxide. $J$ Am Ceram Soc 1961;44:116-20.

13. Pettit FS, Randklev EH, Felten EJ. Formation of $\mathrm{NiAl}_{2} \mathrm{O}_{4}$ by solid state formation. J Am Ceram Soc 1966;49(4):199-203.

14. Li DX, Pirouz P, Heuer AH, Yadavalli S, Flynn CP. A high-resolution electron-microscopy study of $\mathrm{MgO} / \mathrm{Al}_{2} \mathrm{O}_{3}$ interface and $\mathrm{MgAl}_{2} \mathrm{O}_{4}$ spinel formation. Philos Mag A 1992;65(2):403-25.

15. Whitney WP, Stubican VS. Interdiffusion in system $\mathrm{MgO}-\mathrm{MgAl}_{2} \mathrm{O}_{4} . J A m$ Ceram Soc 1971;54(7):349-52. 
16. Navias L. Preparation and properties of spinel made by vapor transport and diffusion in the system $\mathrm{MgO}-\mathrm{Al}_{2} \mathrm{O}_{3} . J$ Am Ceram Soc 1961;44(9):434-46.

17. Okada H, Kawakami H, Hashiba M, Miura E, Nurishi Y, Hibino T. Effect of physical nature of powders and firing atmosphere on $\mathrm{ZnAl}_{2} \mathrm{O}_{4}$ formation. J Am Ceram Soc 1985;68(2):58-63.

18. Roy DM, Roy R, Osborn EF. System $\mathrm{MgO} \cdot \mathrm{Al}_{2} \mathrm{O}_{3}-\mathrm{Al}_{2} \mathrm{O}_{3}$. J Am Ceram Soc 1953;36(5):149.

19. Nuns N, Beclin F, Crampon J. Grain-boundary characterization in a nonstoichiometric fine-grained magnesium aluminate spinel: effects of defect segregation at the space-charge layers. J Am Ceram Soc 2009;92(4): $870-5$.

20. Ting CJ, Lu HY. Defect reactions and the controlling mechanism in the sintering of magnesium aluminate spinel. J Am Ceram Soc 1999;82(4): 841-8.

21. Ball JA, Murphy ST, Grimes RW, Bacorisen D, Smith R, Uberuaga BP, et al. Defect processes in $\mathrm{MgAl}_{2} \mathrm{O}_{4}$ spinel. Solid State Sci 2008;10 $717-24$.

22. Okuyama Y, Kurita N, Fukatsu N. Defect structure of aluminarich nonstoichiometric magnesium aluminate spinel. Solid State Ionics 2006;177:59-64.

23. Murphy ST, Uberuaga BP, Ball JB, Cleave AR, Sickafus KE, Smithe R, et al. Cation diffsusion in magnesium aluminate spinel. Solid State Ionics 2009;180:1-8.

24. Sheldon RI, Hartmann T, Sickafus KE, Ibarra A, Scott BL, Argyriou $\mathrm{DN}$, et al. Cation disorder and vacancy distribution in nonstoichiometric magnesium aluminate spinel, $\mathrm{MgO} \cdot x \mathrm{Al}_{2} \mathrm{O}_{3}$. J Am Ceram Soc 1999;82(12):3293-8.

25. Carry C, Yalamaç E, Akkurt S. Co-Sintering behaviours of oxide based bi-materials. In: Olevsky EA, Bordia RK, editors. Book series; Ceramic Transactions. Advances in sintering science and technology, vol. 209. New York: Wiley; 2010. p. 307-20.
26. Yalamac E. Sintering, co-sintering and microstructure control of oxide based materials: zirconia, alumina, spinel, alumina-zirconia and spinel-alumina. Izmir Institute of Technology - Izmir(TR)/Grenoble University - Grenoble(FR); 2010.

27. Ting CJ, Lu HY. Deterioration in the final-stage sintering of magnesium aluminate spinel. J Am Ceram Soc 2000;83(7):1592-8.

28. Schmalzried H. Chemical kinetics at solid-solid interfaces. Pure Appl Chem 2000;72(11):2137-47.

29. Wright SI, Field DP, Dingley DJ. Advanced software capabilities for automated EBSD. In: Schwartz AJ, Kumar M, Adams BL, editors. Electron backscatter diffraction in materials science. Kluwer Academic/Plenum Publishers; 2000. p. 141-52 [chapter 13].

30. Kotula P. Ceramic thin film reaction: nucleation and kinetics. Minneapolis: Department of Chemical Engineering and Materials Science, University of Minnesota; 1996.

31. Reimanis I, Kleebe HJ. A review on the sintering and microstructure development of transparent spinel $\left(\mathrm{MgAl}_{2} \mathrm{O}_{4}\right)$. J Am Ceram Soc 2009;92(7):1472-80.

32. Sasamoto T, Hara H, Sata T. Mass-spectrometric study of the vaporization of magnesium-oxide from magnesium aluminate spinel. Bull Chem Soc Jpn 1981;54(11):3327-33.

33. Hallstedt $\mathrm{B}$. Thermodynamic assessment of the system $\mathrm{MgO}-\mathrm{Al}_{2} \mathrm{O}_{3} . J \mathrm{Am}$ Ceram Soc 1992;75(6):1497-507.

34. Altman R. Vaporization of magnesium oxide and its reaction with alumina. J Am Ceram Soc 1963;67:366-9.

35. Bratton RJ. Sintering and grain-growth kinetics of $\mathrm{MgAl}_{2} \mathrm{O}_{4}$. J Am Ceram Soc 1971;54(3):141-3.

36. Röttger R, Schmalzried H. Chemical kinetics at solid/solid interfaces. Solid State Ionics 2002;150:131-41.

37. Baikowski. Available from: http://www.baikowski.com [accessed 10.03.10]. 